\title{
BMJ Open Are noise and air pollution related to the incidence of dementia? A cohort study in London, England
}

\author{
lain M Carey, ${ }^{1} \mathrm{H}$ Ross Anderson, ${ }^{1,2}$ Richard W Atkinson, ${ }^{1}$ Sean D Beevers, ${ }^{2}$ \\ Derek G Cook, ${ }^{1}$ David P Strachan, ${ }^{1}$ David Dajnak, ${ }^{2}$ John Gulliver, ${ }^{3}$ Frank J Kelly ${ }^{2,4}$
}

To cite: Carey IM, Anderson HR, Atkinson RW, et al. Are noise and air pollution related to the incidence of dementia? A cohort study in London, England. BMJ Open 2018;8:e022404. doi:10.1136/ bmjopen-2018-022404

- Prepublication history and additional material for this paper are available online. To view these files, please visit the journal online (http://dx.doi. org/10.1136/bmjopen-2018022404).

Received 16 February 2018

Revised 21 May 2018

Accepted 20 June 2018

A Check for updates

(c) Author(s) (or their employer(s)) 2018. Re-use permitted under CC BY-NC. No commercial re-use. See rights and permissions. Published by BMJ.

${ }^{1}$ Population Health Research Institute, St George's, University of London, London, UK ${ }^{2}$ MRC-PHE Centre for Environment and Health, King's College London, London, UK ${ }^{3}$ UK Small Area Health Statistics Unit, MRC-PHE Centre for Environment and Health, Imperial College, London, UK ${ }^{4} \mathrm{NIHR}$ HealthProtection

Research Unit in Health Impact of Environmental Hazards, King's College London, London, UK

Correspondence to

Dr lain M Carey;

sgjd450@sgul.ac.uk

\section{ABSTRACT}

Objective To investigate whether the incidence of dementia is related to residential levels of air and noise pollution in London.

Design Retrospective cohort study using primary care data.

Setting 75 Greater London practices.

Participants 130978 adults aged $50-79$ years registered with their general practices on 1 January 2005, with no recorded history of dementia or care home residence. Primary and secondary outcome measures A first recorded diagnosis of dementia and, where specified, subgroups of Alzheimer's disease and vascular dementia during 2005-2013. The average annual concentrations during 2004 of nitrogen dioxide $\left(\mathrm{NO}_{2}\right)$, particulate matter with a median aerodynamic diameter $\leq 2.5 \mu \mathrm{m}\left(\mathrm{PM}_{2.5}\right)$ and ozone $\left(0_{3}\right)$ were estimated at $20 \times 20 \mathrm{~m}$ resolution from dispersion models. Traffic intensity, distance from major road and night-time noise levels $\left(\mathrm{L}_{\text {night }}\right)$ were estimated at the postcode level. All exposure measures were linked anonymously to clinical data via residential postcode. HRs from Cox models were adjusted for age, sex, ethnicity, smoking and body mass index, with further adjustments explored for area deprivation and comorbidity.

Results 2181 subjects $(1.7 \%)$ received an incident diagnosis of dementia (39\% mentioning Alzheimer's disease, $29 \%$ vascular dementia). There was a positive exposure response relationship between dementia and all measures of air pollution except $\mathrm{O}_{3}$, which was not readily explained by further adjustment. Adults living in areas with the highest fifth of $\mathrm{NO}_{2}$ concentration $\left(>41.5 \mu \mathrm{g} / \mathrm{m}^{3}\right)$ versus the lowest fifth $\left(<31.9 \mu \mathrm{g} / \mathrm{m}^{3}\right)$ were at a higher risk of dementia ( $\mathrm{HR}=1.40,95 \% \mathrm{Cl} 1.12$ to 1.74$)$. Increases in dementia risk were also observed with $\mathrm{PM}_{2.5}, \mathrm{PM}_{2.5}$ specifically from primary traffic sources only and $L_{\text {night' }}$, but only $\mathrm{NO}_{2}$ and $\mathrm{PM}_{2.5}$ remained statistically significant in multipollutant models. Associations were more consistent for Alzheimer's disease than vascular dementia.

Conclusions We have found evidence of a positive association between residential levels of air pollution across London and being diagnosed with dementia, which is unexplained by known confounding factors.

\section{BACKGROUND}

Dementia, encompassing both vascular dementia and Alzheimer's disease, is now reported as the leading cause of death in

\section{Strengths and limitations of this study}

- Annual concentrations during 2004 for air and noise pollution exposure were modelled at a fine resolution, including near-road estimates of traffic pollution.

- Pollution data were anonymously linked to electronic health records of over 100000 older adults registered with 75 general practices in Greater London during 2005-2013.

- Incident dementia diagnoses were identified, including Alzheimer's disease and vascular dementia.

- The robustness of the results was tested for by adjusting for area deprivation and other comorbidities.

- Accuracy and completeness of primary care diagnoses of dementia and subdiagnoses are a known issue.

England and Wales, accounting for $12 \%$ of all registered deaths. ${ }^{1}$ While temporal changes in recording may have influenced how the underlying cause is now determined, more important are increases in longevity among the population at older ages, caused by declining trends in deaths from cardiovascular and cerebrovascular disease. ${ }^{2}$ In terms of years of life lost, the Global Burden of Disease in 2013 ranked all dementia as the fifth leading cause, ${ }^{2}$ noting their increasing importance as a cause of death despite little change in age-standardised rates. Therefore, primary prevention of all dementia is a major global public health concern for the coming decades. ${ }^{3}$ For Alzheimer's disease for example, while it has been estimated that small delays in its onset and progression could significantly reduce its estimated future burden, ${ }^{4}$ research has primarily focused on lifestyle factors, where a large systematic review estimated that about a third of Alzheimer's disease may be attributable to potentially modifiable risk factors such as smoking and physical inactivity. ${ }^{5}$

More recently research has also extended to the role of environmental risk factors 
and dementia, where a large systematic review identified moderate evidence for an association with eight different factors including air pollution. ${ }^{6}$ While air pollution is a well-established risk factor for cardiovascular and respiratory disease, ${ }^{7}$ its role in relation to dementia is less well considered and understood. ${ }^{8}$ A recent systematic review of the epidemiological evidence linking air pollution to dementia-related outcomes identified 18 studies, with most reporting adverse associations. ${ }^{9}$ However, there was a significant variation in the size and quality of the studies involved, reiterating the noted lack of robust longitudinal or population-based studies. ${ }^{68}$ Subsequently, a large population-based study in Ontario, Canada, reported that living close to major roads was associated with a higher incidence of dementia, ${ }^{10}$ with a further analysis revealing corresponding associations with modelled levels of nitrogen dioxide $\left(\mathrm{NO}_{2}\right)$ and mass of fine particulate matter with a median aerodynamic diameter $\leq 2.5 \mu \mathrm{m}\left(\mathrm{PM}_{2.5}\right){ }^{11}$ These findings raise questions around the mechanisms for the early development of neuroinflammation and neurodegeneration, ${ }^{12}$ and require further exploration and replication in other large population cohorts with different exposure models, including traffic noise which has been linked to cognitive decline in adults. ${ }^{13}$

In this paper, we use modelled estimates at a fine spatial scale for modelled estimates of air and noise pollution to investigate relationships with the incidence of dementia across Greater London.

\section{METHODS}

\section{Data source}

The Clinical Practice Research Datalink (CPRD) is a large, validated primary care database that has been collecting anonymous patient data from participating UK general practices since $1987 .{ }^{14}$ It has been shown to be broadly representative of the UK population, with about $7 \%$ of all people in the UK actively registered on it in 2011. ${ }^{14}$ Approximately three-quarters of contributing CPRD practices in England have consented to their data being linked to external sources. This is facilitated by a 'trusted third party' to CPRD, ensuring that researchers have no access to geographical identifiers such as residential postcode. Key variables which have been linked to the practice data include the Index of Multiple Deprivation (IMD), a composite small-area (approximately 1500 people) measure used in England for allocation of resources, ${ }^{15}$ and the Office for National Statistics death registration data, which allows underlying cause of death to be identified. For this study, we selected 75 (linked) practices that lay within the study area bounded geographically by the orbital M25 motorway around Greater London (60 were in outer London boroughs, 15 were in inner London boroughs) that were continually recording data between 2004 and $2010 .^{16}$

\section{Estimates of air and noise pollution exposure}

The following measures of exposure, estimated annually between 2004 and 2010, were linked to CPRD: (1) air pollution concentrations, (2) traffic intensity or distance measures, and (3) road traffic noise levels. A priori we chose to focus on annual concentrations estimated in 2004 as this was the earliest year linked. Modelled estimates in other years (2005-2010) were highly correlated $(\mathrm{r}>0.95)$, and repeating the analysis using alternative years produced identical results (data not shown).

Modelled annual concentrations for air pollutants were estimated using the KCLurban dispersion modelling system at a resolution of $20 \times 20 \mathrm{~m} .{ }^{17}$ It incorporates hourly meteorological measurements, empirically derived

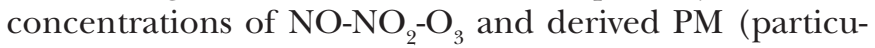
late matter), using information on source emissions from the London Atmospheric Emissions Inventory. ${ }^{18}$ For this analysis, we focused on annual concentrations in 2004 for $\mathrm{NO}_{2}, \mathrm{PM}_{2.5}$ (fine particulate matter with a median aerodynamic diameter $\leq 2.5 \mu \mathrm{m}$ ) and $\mathrm{O}_{3}$ (ozone). Additionally, we present an estimate for primary $\mathrm{PM}_{2.5}$ attributable to road traffic sources estimated from the sum of contributions from the following emission sources: tyre, brake, exhaust, surface wear and resuspension. ${ }^{17}$ Air pollution concentration estimates were derived for each of the 190115 London postcodes address centroids based on interpolation from the closest $20 \times 20 \mathrm{~m}$ point of the dispersion model. ${ }^{18}$ This resulted in patients residing in the same postcodes, which typically average about 15 households nationally, being assigned the same exposure levels. Additionally, some postcodes covering smaller geographical areas may also be assigned to the same $20 \times 20 \mathrm{~m}$ point. The exposure concentrations were linked to CPRD by the 'trusted third party', who subsequently remove the postcode, ensuring we had no direct access to any geographical identifiers.

Traffic proximity measures were developed relating to 'heavy' vehicle density, which was defined as light goods vehicles, heavy goods vehicles (rigid and articulated trucks/lorries), buses and coaches. We included a distance measure (in metres) from the postcode centroid to the nearest road classified in the top quartile of heavy vehicle intensity. Traffic intensity was estimated as total vehicle kilometre driven (heavy vehicles only) in each year for all major roads that fell within a $50 \mathrm{~m}$ and $50-100 \mathrm{~m}$ radius of the postcode address centroid. We used an arbitrary cut-off of $>100000 \mathrm{~km}$ driven to define 'high volume' in the analyses.

Road traffic noise levels were estimated using the TRAffic Noise EXposure (TRANEX) model. ${ }^{19}$ This uses information on road traffic flows and speeds, road geography, land cover, and building heights to estimate average sound pressure level $\left(\mathrm{LA}_{\mathrm{eq}}\right)$ in decibels $(\mathrm{dB})$ over different time periods. Evaluations of TRANEX in two other English cities have shown high correlation $(\mathrm{r} \geq 0.85)$ between modelled and measured 1-hour $\mathrm{LA}_{\text {eq }}{ }^{19}$ In our analysis, we focused on the average annual $\mathrm{L}_{\text {night }}$ recorded overnight between 23:00 and 07:00, as this period 
represents when most of our study subjects would be at their residence. Alternative analyses using daytime noise $\left(\mathrm{LA}_{\text {eq16 }}\right)$ produced identical results (data not shown) due to the extremely high correlation with night noise $(r=0.999) .{ }^{20}$ For the linkage of the noise model to CPRD, the geometric centroids of the address locations in each postcode were directly used.

\section{Cohort definition}

Among the 75 practices, a total of 555385 patients were actively registered on 1 January 2005, representing about $7 \%$ of the Greater London population at that time. From these, we selected 139718 adults aged 50-79 years who had been registered for $\geq 1$ year continuously with their practice. From this group, 131869 (94\%) were successfully linked to our pollution exposures. Non-linkage was mainly due to a few practices being near the study area boundary, so many of their patients' individual postcodes were not eligible. Patients were followed until the earliest of (1) date of first diagnosis of dementia, (2) date of death or deregistration from practice, (3) date when the practice ceased contributing to CPRD and (4) 31 December 2013.

We searched the primary care records for the date of first dementia diagnosis, using the Read codes for dementia within the Quality and Outcomes Framework (QOF). ${ }^{21}$ Although most Read codes are non-specific, we identified subgroups that classified the dementia as Alzheimer's disease or vascular dementia. Using the death records, we also used the International Classification of Diseases 10th Revision codes to identify patients with dementia listed as the primary cause of death (if not coded as such on the general practitioner (GP) record), and to further classify them based on specific mention of Alzheimer's disease or vascular dementia anywhere on the death record. We also extracted from the GP record information on ethnicity, smoking, body mass index (BMI) and alcohol consumption, using the last measurement before baseline when available, or during the study if that was the only one available. A missing category was retained where no information was available. In addition, we extracted information on comorbidity recorded at baseline, based on a list of conditions we have previously shown to be independently predictive of mortality. ${ }^{22}$

Patients $(n=391)$ with an existing diagnosis of dementia by 1 January 2005 were excluded. Additionally, we sought to exclude patients $(n=423)$ when there was evidence on their medical record that they were living in a residential or care home as of 1 January 2005 . We did this through a combination of Read codes, or where four or more patients aged 65-99 were recorded living at the same address. We also excluded a small number of patients $(\mathrm{n}=77)$ where no IMD could be assigned. This resulted in 130978 eligible patients for our analyses.

\section{Statistical analyses}

We used Cox proportional hazards models to investigate the associations between all exposure measures estimated in the year before baseline (2004) and subsequent dementia incidence. To account for the clustering by practice (homogeneity between patients from the same practice), we fitted models with a shared frailty (at practice level), which are the survival data equivalent to random effects. ${ }^{23}$ We adjusted cumulatively for (1) age, sex, ethnicity, smoking and BMI (recorded alcohol consumption was not independently predictive and was dropped from the model), (2) IMD decile (based on national ranking across England) and (3) comorbidities (ischaemic heart disease (IHD), stroke, heart failure, diabetes) that were independently predictive of dementia. For model (2) we explored the effect of adjusting for other pollutants (air pollution for noise and vice versa). In sensitivity analyses, we explored within-practice and between-practice effects by fitting different models (a non-frailty model stratified on practice, practice fitted as a fixed effect, fitting practice mean exposure level in addition to individual level). For all pollutants, we fitted a continuous measure based on IQR to enable comparison between estimates, and quintiles to describe the shape of the association. All analyses were carried out in Stata V.13.

\section{Patient and public involvement}

No patients were involved in developing the research question, outcome measures and overall design of the study. Due to patient anonymity, we are unable to disseminate the results of the research directly to study participants.

\section{RESULTS}

During the study follow-up period (mean=6.9 years), a total of 2181 patients $(1.7 \%$, incidence rate 2.4 per 1000 per year) received a first diagnosis of dementia during follow-up (table 1). Among those patients diagnosed, $848(38.9 \%)$ had a mention of Alzheimer's disease, 634 (29.1\%) mentioned vascular dementia, while 747 (34.3\%) received a non-specific Read code. A total of 48 patients $(2.2 \%)$ received diagnoses for both Alzheimer's disease and vascular dementia. While crude incidence rates for dementia were lowest in smokers, later adjustment for age and other covariates explained this association; however, the lowest dementia risk seen in obese subjects persisted (data not shown).

The summary statistics for the modelled air and noise pollutants in 2004 are shown in table 2. All air pollutants were strongly positively related to each other $(r>0.9)$, except for $\mathrm{O}_{3}$ which was negatively correlated $(\mathrm{r}=-0.9$ or greater) with both $\mathrm{NO}_{2}$ and $\mathrm{PM}_{2.5}$. Night noise $\left(\mathrm{L}_{\text {night }}\right)$ was positively related to $\mathrm{NO}_{2}$ and $\mathrm{PM}_{2.5}$, but associations were less in magnitude $(\mathrm{r}=0.3-0.4)$ to all air pollutants. A different pattern for noise was also observed when intraclass correlations (ICCs) were calculated by practice. While most variation by noise was observed within practices $(\mathrm{ICC}=0.05)$, the opposite was true for air pollutants where most variation was between practice $($ ICC $>0.7)$. When mean concentrations were calculated by traffic distance and intensity (online supplementary table S1), 
Table 1 Incidence rates of dementia during follow-up by characteristics of eligible subjects estimated at baseline

\begin{tabular}{|c|c|c|c|c|c|c|c|c|c|c|c|}
\hline \multirow{2}{*}{$\begin{array}{l}\text { Baseline } \\
\text { variable }\end{array}$} & \multirow{2}{*}{ Grouping } & & & \multicolumn{8}{|c|}{ First diagnosis of dementia 2005-2013† } \\
\hline & & \multicolumn{2}{|c|}{ All subjects } & \multicolumn{2}{|l|}{ Any } & \multicolumn{2}{|c|}{$\begin{array}{l}\text { Alzheimer's } \\
\text { disease }\end{array}$} & \multicolumn{2}{|c|}{ Vascular } & \multicolumn{2}{|c|}{ Non-specific } \\
\hline & All & 130978 & 100 & 2181 & 2.40 & 848 & 0.93 & 634 & 0.69 & 747 & 0.82 \\
\hline Sex & Men & 65130 & 49.7 & 948 & 2.14 & 326 & 0.73 & 301 & 0.68 & 344 & 0.78 \\
\hline \multirow{2}{*}{ Age } & $60-69$ & 41013 & 31.3 & 427 & 1.49 & 175 & 0.61 & 102 & 0.36 & 155 & 0.54 \\
\hline & $70-79$ & 30378 & 23.2 & 1655 & 8.27 & 635 & 3.14 & 515 & 2.54 & 547 & 2.70 \\
\hline \multirow[t]{2}{*}{ Ethnicity } & White & 86896 & 66.3 & 1791 & 2.84 & 703 & 1.11 & 524 & 0.83 & 607 & 0.96 \\
\hline & Asian & 7309 & 5.6 & 98 & 1.77 & 35 & 0.63 & 39 & 0.70 & 27 & 0.49 \\
\hline \multirow{3}{*}{ Smoking } & Ex & 33063 & 25.2 & 715 & 3.10 & 264 & 1.14 & 235 & 1.01 & 235 & 1.01 \\
\hline & Current & 25733 & 19.7 & 308 & 1.76 & 95 & 0.54 & 89 & 0.51 & 133 & 0.76 \\
\hline & Missing & 8704 & 6.7 & 50 & 1.09 & 16 & 0.35 & 17 & 0.37 & 17 & 0.37 \\
\hline \multirow[t]{5}{*}{ BMI } & $<20$ & 5188 & 4.0 & 173 & 5.09 & 66 & 1.93 & 52 & 1.52 & 58 & 1.69 \\
\hline & $20-25$ & 35642 & 27.2 & 702 & 2.81 & 276 & 1.10 & 201 & 0.80 & 237 & 0.94 \\
\hline & $25-30$ & 41281 & 31.5 & 721 & 2.44 & 304 & 1.02 & 202 & 0.68 & 238 & 0.80 \\
\hline & $30+$ & 25783 & 19.7 & 364 & 1.97 & 116 & 0.63 & 129 & 0.70 & 125 & 0.68 \\
\hline & Missing & 23084 & 17.6 & 221 & 1.51 & 86 & 0.59 & 50 & 0.34 & 89 & 0.61 \\
\hline \multirow[t]{2}{*}{ Heart failure } & Yes & 1704 & 1.3 & 62 & 6.76 & 9 & 0.97 & 26 & 2.81 & 27 & 2.92 \\
\hline & No & 129274 & 98.7 & 2119 & 2.35 & 839 & 0.93 & 608 & 0.67 & 720 & 0.80 \\
\hline \multirow[t]{5}{*}{ IMD‡ } & 1 (least) & 26149 & 20.0 & 426 & 2.21 & 163 & 0.84 & 132 & 0.68 & 144 & 0.75 \\
\hline & 2 & 31452 & 24.0 & 535 & 2.36 & 212 & 0.93 & 146 & 0.64 & 188 & 0.83 \\
\hline & 3 & 26093 & 19.9 & 401 & 2.29 & 179 & 1.02 & 112 & 0.64 & 119 & 0.68 \\
\hline & 4 & 30817 & 23.5 & 514 & 2.49 & 187 & 0.90 & 160 & 0.77 & 176 & 0.85 \\
\hline & 5 (most) & 16467 & 12.6 & 305 & 2.78 & 107 & 0.97 & 84 & 0.76 & 120 & 1.09 \\
\hline \multirow[t]{2}{*}{ Borough } & Inner & 23111 & 17.6 & 390 & 2.51 & 123 & 0.79 & 134 & 0.86 & 143 & 0.92 \\
\hline & Outer & 107867 & 82.4 & 1791 & 2.37 & 725 & 0.96 & 500 & 0.66 & 604 & 0.80 \\
\hline \multirow{2}{*}{$\begin{array}{l}\text { Registration } \\
\text { length (years) }\end{array}$} & $<10$ & 40386 & 30.8 & 638 & 2.41 & 251 & 0.94 & 196 & 0.74 & 210 & 0.79 \\
\hline & $10+$ & 90592 & 69.2 & 1543 & 2.39 & 597 & 0.92 & 438 & 0.68 & 537 & 0.83 \\
\hline
\end{tabular}

*Incidence rate per 1000 patients per year.

$\mathrm{t}=48$ patients appear in both Alzheimer's disease and vascular dementia categories.

†These groups correspond to the fifths of the IMD ranking across England; thus, Greater London is under-represented in the most deprived fifth.

BMI, body mass index; IHD, ischaemic heart disease; IMD, Index of Multiple Deprivation. 


\begin{tabular}{|c|c|c|c|c|c|c|}
\hline $\begin{array}{l}\text { Summary } \\
\text { statistics }\end{array}$ & & $\begin{array}{l}\mathrm{NO}_{2} \\
\left(\mu \mathrm{g} / \mathrm{m}^{3}\right)\end{array}$ & $\begin{array}{l}\mathrm{PM}_{2.5} \\
\left(\mu \mathrm{g} / \mathrm{m}^{3}\right)\end{array}$ & $\begin{array}{l}\mathrm{PM}_{2.5} \text { (traffic) } \\
\left(\mu \mathrm{g} / \mathrm{m}^{3}\right)\end{array}$ & $\begin{array}{l}O_{3} \\
\left(\mu g / m^{3}\right)\end{array}$ & $\begin{array}{l}L_{\text {night }} \\
\text { (dB) }\end{array}$ \\
\hline Mean \pm SD & & $37.1 \pm 5.7$ & $15.7 \pm 0.8$ & $1.4 \pm 0.5$ & $38.0 \pm 3.9$ & $52.1 \pm 4.6$ \\
\hline Median (IQR) & & $36.4(32.9-40.4)$ & $15.6(15.2-16.1)$ & $1.3(1.1-1.7)$ & $38.2(35.5-41.0)$ & $49.9(49.4-52.1)$ \\
\hline \multirow[t]{6}{*}{$\begin{array}{l}\text { Correlation } \\
\text { coefficients }\end{array}$} & $\mathrm{NO}_{2}$ & - & 0.98 & 0.94 & -0.99 & 0.33 \\
\hline & $\mathrm{PM}_{2.5}$ & 0.98 & - & 0.97 & -0.96 & 0.39 \\
\hline & $\mathrm{PM}_{2.5}$ (traffic) & 0.94 & 0.97 & - & -0.90 & 0.51 \\
\hline & $\mathrm{O}_{3}$ & -0.99 & -0.96 & -0.90 & - & -0.27 \\
\hline & $\mathrm{L}_{\text {night }}$ & 0.33 & 0.39 & 0.51 & -0.27 & - \\
\hline & ICC (practice)* & 0.87 & 0.83 & 0.68 & 0.92 & 0.05 \\
\hline
\end{tabular}

*Intraclass coefficient calculated across practice clusters.

$\mathrm{L}_{\text {night }}$, night-time noise levels; $\mathrm{NO}_{2}$, nitrogen dioxide; $\mathrm{O}_{3}$, ozone; $\mathrm{PM}_{2.5}$, particulate matter $\leq 2.5 \mu \mathrm{m}$.

all pollutants declined with increasing distance from major roads, except $\mathrm{O}_{3}$ which was higher with further distance. While patients residing in postcodes closest to major roads $(0-50 \mathrm{~m})$ had much higher night noise levels than those farthest away $(60.4 \mathrm{~dB}$ vs $50.9 \mathrm{~dB})$, the difference in modelled air pollution concentrations, especially $\mathrm{PM}_{2.5}$, was much less.

Table 3 summarises a series of adjusted HRs for an incident diagnosis of dementia associated with comparable interquartile changes in different pollutant exposures. The strongest positive associations were seen for $\mathrm{NO}_{2}$, where $\mathrm{a}+7.5 \mu \mathrm{g} / \mathrm{m}^{3}$ change produced an HR of 1.16 (95\% CI 1.05 to 1.28), adjusting for IMD and other confounders (HR2 in table 3). Further adjustment for related comorbidities (HR3=1.16) did not explain this association. Corresponding associations were smaller with other measures $\left(\mathrm{PM}_{2.5} \mathrm{HR}=1.07, \mathrm{PM}_{2.5}\right.$ traffic $\mathrm{HR}=1.08$, $\mathrm{L}_{\text {night }} \mathrm{HR}=1.02$, distance from road $\mathrm{HR}=1.02$ ) or negative $\left(\mathrm{O}_{3} \mathrm{HR}=0.84\right)$. We explored different approaches in estimating within-practice and between-practice estimates (online supplementary table S2). For $\mathrm{NO}_{2}$ and $\mathrm{PM}_{2.5}$ the HRs were $>1$ for both estimates, but the CIs were wide. For night noise $\left(\mathrm{L}_{\text {night }}\right)$, there was stronger evidence suggesting between-practice association ( $\mathrm{HR}=1.42$, 95\% CI 1.03 to 1.96). To investigate the shape of the association, figure 1 plots the adjusted HR (HR3 in table 3) by air and noise pollution fifths, and road distance and traffic intensity $50 \mathrm{~m}$ categories. The corresponding HRs are given in full in online supplementary table S3. For $\mathrm{NO}_{2}$ and $\mathrm{PM}_{2.5}$ the increase in dementia risk was noticeably higher in the top fifth of exposure. Patients with an assigned annual exposure of $\mathrm{NO}_{2}$ of $>41.5 \mu \mathrm{g} / \mathrm{m}^{3}$ had a marked increase in risk $(\mathrm{HR}=1.40,95 \%$ CI 1.12 to 1.74$)$ compared with those in the bottom fifth $\left(<31.9 \mu \mathrm{g} / \mathrm{m}^{3}\right)$. For other measures (noise, distance, intensity), there was less evidence of any trend, while for $\mathrm{O}_{3}$ the risk was highest in the lowest fifth of exposure $\left(<34.7 \mu \mathrm{g} / \mathrm{m}^{3}\right)$.

The associations between dementia and an interquartile change $\left(+7.5 \mu \mathrm{g} / \mathrm{m}^{3}\right)$ in $\mathrm{NO}_{2}$ are explored further in figure 2, which plots the adjusted HRs (HR2 in table 3) from Cox models stratified on a series of risk factors. Generally, there was little evidence of any effect modification across these factors, with all categories producing an $\mathrm{HR}>1$. Associations between $\mathrm{NO}_{2}$ and dementia were still observed when restricted to patients registered for their practice continually for more than 10 years $(\mathrm{HR}=1.13$,

Table 3 Adjusted HRs for incident dementia during 2005-2013 by air and noise pollutants

\begin{tabular}{|c|c|c|c|c|c|}
\hline Exposure & IQR change & $\mathrm{HR1}^{*}(95 \% \mathrm{Cl})$ & HR2† (95\% CI) & HR3¥ (95\% Cl) & HR4§ (95\% Cl) \\
\hline $\mathrm{NO}_{2}$ & $+7.47 \mu \mathrm{g} / \mathrm{m}^{3}$ & 1.17 (1.06 to 1.28$)$ & 1.16 (1.05 to 1.28$)$ & 1.16 (1.05 to 1.27$)$ & 1.15 (1.04 to 1.28$)$ \\
\hline $\mathrm{PM}_{2.5}$ & $+0.95 \mu \mathrm{g} / \mathrm{m}^{3}$ & 1.07 (1.02 to 1.12$)$ & 1.07 (1.02 to 1.12$)$ & 1.06 (1.02 to 1.12$)$ & 1.06 (1.01 to 1.13 ) \\
\hline $\mathrm{PM}_{2.5}$ (traffic) & $+0.58 \mu \mathrm{g} / \mathrm{m}^{3}$ & 1.09 (1.02 to 1.17$)$ & 1.08 (1.01 to 1.16$)$ & 1.08 (1.01 to 1.16$)$ & 1.08 (0.99 to 1.18$)$ \\
\hline $\mathrm{O}_{3}$ & $+5.56 \mu \mathrm{g} / \mathrm{m}^{3}$ & 0.84 (0.75 to 0.93 ) & 0.84 (0.75 to 0.94$)$ & 0.85 (0.76 to 0.94$)$ & 0.85 (0.76 to 0.96$)$ \\
\hline $\mathrm{L}_{\text {night }}$ & $+2.68 \mathrm{~dB}$ & 1.02 (1.00 to 1.05$)$ & 1.02 (1.00 to 1.05$)$ & 1.02 (1.00 to 1.05$)$ & 1.01 (0.98 to 1.03$)$ \\
\hline Distance to major road & $-310 m$ & 1.02 (0.97 to 1.08$)$ & 1.02 (0.97 to 1.08$)$ & 1.02 (0.97 to 1.08$)$ & 1.00 (0.95 to 1.05$)$ \\
\hline
\end{tabular}

*HR1: Cox model with practice fitted as shared frailty. Adjusted for age, sex, ethnicity, smoking and body mass index. †HR2: As HR1, plus additional adjustment for Index of Multiple Deprivation.

†HR3: As HR2, plus additional adjustment for comorbidity (ischaemic heart disease, stroke, diabetes, heart failure). §HR4: As HR2, plus additional adjustment for $\mathrm{L}_{\text {night }}\left(\mathrm{NO}_{2}\right.$ and $\mathrm{PM}_{2.5}$ estimates) or $\mathrm{NO}_{2}\left(\mathrm{~L}_{\text {night }}\right.$ and distance estimates). $\mathrm{L}_{\text {night }}$, night-time noise levels; $\mathrm{NO}_{2}$, nitrogen dioxide; $\mathrm{O}_{3}$, ozone; $\mathrm{PM}_{2.5}$, particulate matter $\leq 2.5 \mu \mathrm{m}$. 


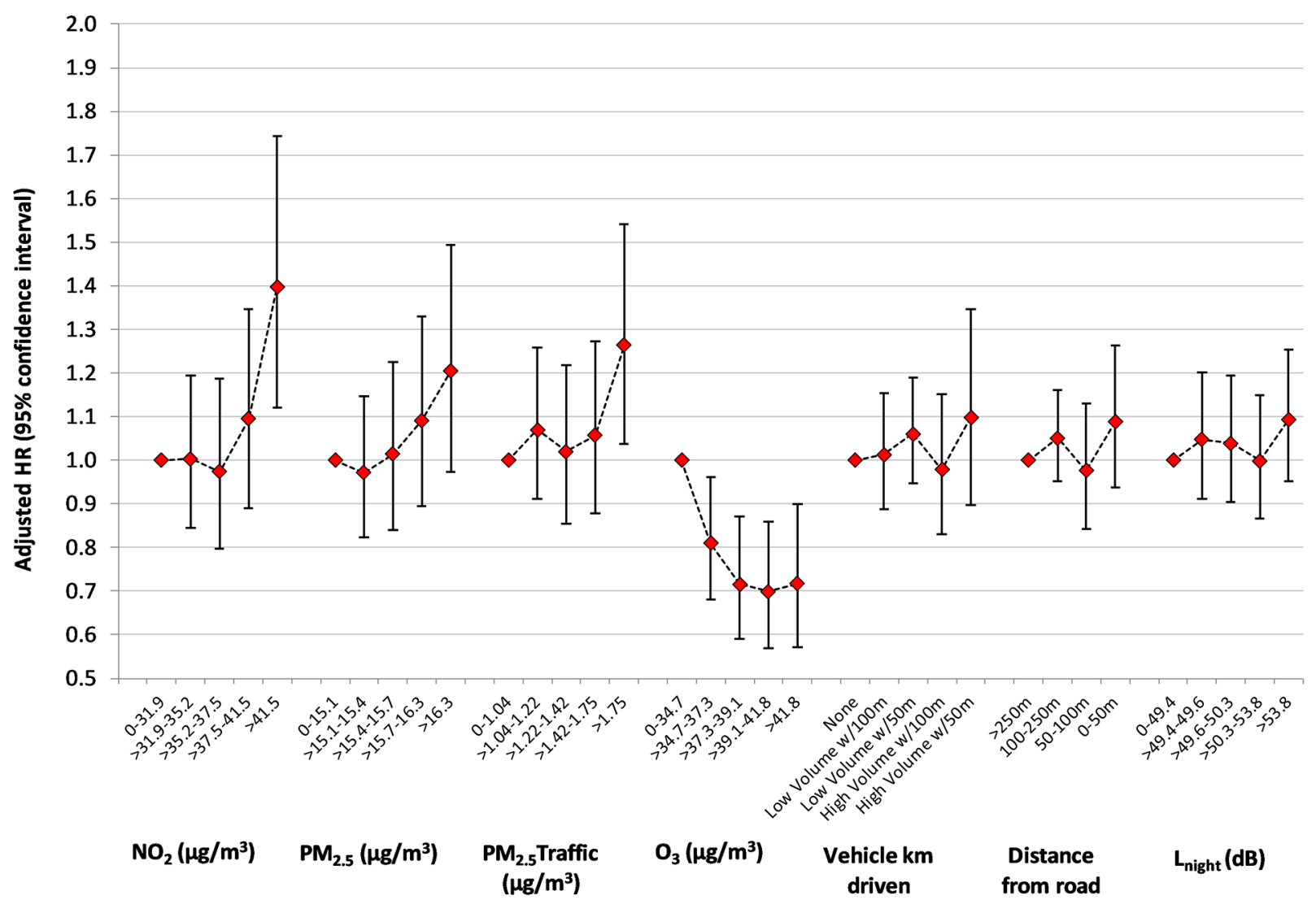

Figure 1 Adjusted HRs for all incident dementia during 2005-2013 by air and noise pollution fifths and traffic distance and intensity categories. HRs estimated from the Cox model with practice fitted as shared frailty. Adjusted for age, sex, ethnicity, smoking, body mass index and Index of Multiple Deprivation. HRs are given in full in online supplementary table S3. $L_{\text {night }}$, nighttime noise levels; $\mathrm{NO}_{2}$, nitrogen dioxide; $\mathrm{O}_{3}$, ozone; $\mathrm{PM}_{2.5}$, particulate matter $\leq 2.5 \mu \mathrm{m}$.

95\% CI 1.01 to 1.26 ), or to patients without IHD, stroke, diabetes or heart failure at baseline $(\mathrm{HR}=1.21,95 \% \mathrm{CI}$ 1.08 to 1.34$)$.

We repeated the analysis, now subclassifying dementia diagnoses recorded as Alzheimer's disease, vascular dementia or non-specific where no further information was available (table 4 ). The positive associations with $\mathrm{NO}_{2}$ and $\mathrm{PM}_{2.5}$ were more consistent for Alzheimer's disease and non-specific diagnoses. For example, patients in the top fifth exposure category of $\mathrm{NO}_{2}\left(>41.5 \mu \mathrm{g} / \mathrm{m}^{3}\right)$ were at a higher risk of receiving an Alzheimer's disease diagnosis than patients in the bottom fifth (HR=1.50, 95\% CI 1.08 to 2.08). For vascular dementia, there was less evidence of consistent effects with air or noise pollution.

\section{DISCUSSION}

In a sample of 75 general practices across Greater London, the recording of new dementia diagnoses was positively associated with measures of $\mathrm{NO}_{2}$ and $\mathrm{PM}_{2.5}$ assigned at residential address at the beginning of the incident period. The association could not be explained by confounding and was consistent within subgroups. When we restricted to specific diagnoses, associations were still observed with Alzheimer's disease but not vascular dementia.

\section{Strengths and weaknesses}

While we were able to link pollution exposures to the primary care record to obtain diagnoses of dementia, there are concerns around the variability of dementia diagnoses in UK primary care, ${ }^{24}$ and a recent review has concluded that dementia diagnoses on primary care databases may not be an accurate reflection of the true prevalence. ${ }^{25}$ Under-recording is thought to be a common issue, as the diagnosis is associated with a stigma for many, and GPs may be reluctant to diagnose dementia unless highly certain. ${ }^{26}$ A recent study across 23 London practices increased the prevalence on their QOF dementia registers by $9 \%$ by a simple coding review. ${ }^{26}$ To account for under-recording at baseline, a priori we decided to exclude all patients identified as living in care homes at the beginning of follow-up regardless of dementia diagnosis. During follow-up, we observed broadly similar number of dementia subtypes being newly diagnosed, and since it is expected that about two-thirds of dementia is Alzheimer's disease, ${ }^{27}$ this suggests the under-recording of Alzheimer's disease in particular may be an issue. Under-recording in our study could be problematic if it was related to key practice characteristics such as deprivation, as dementia recording has been shown to be lower among more affluent practices. ${ }^{24}{ }^{28}$ In our 


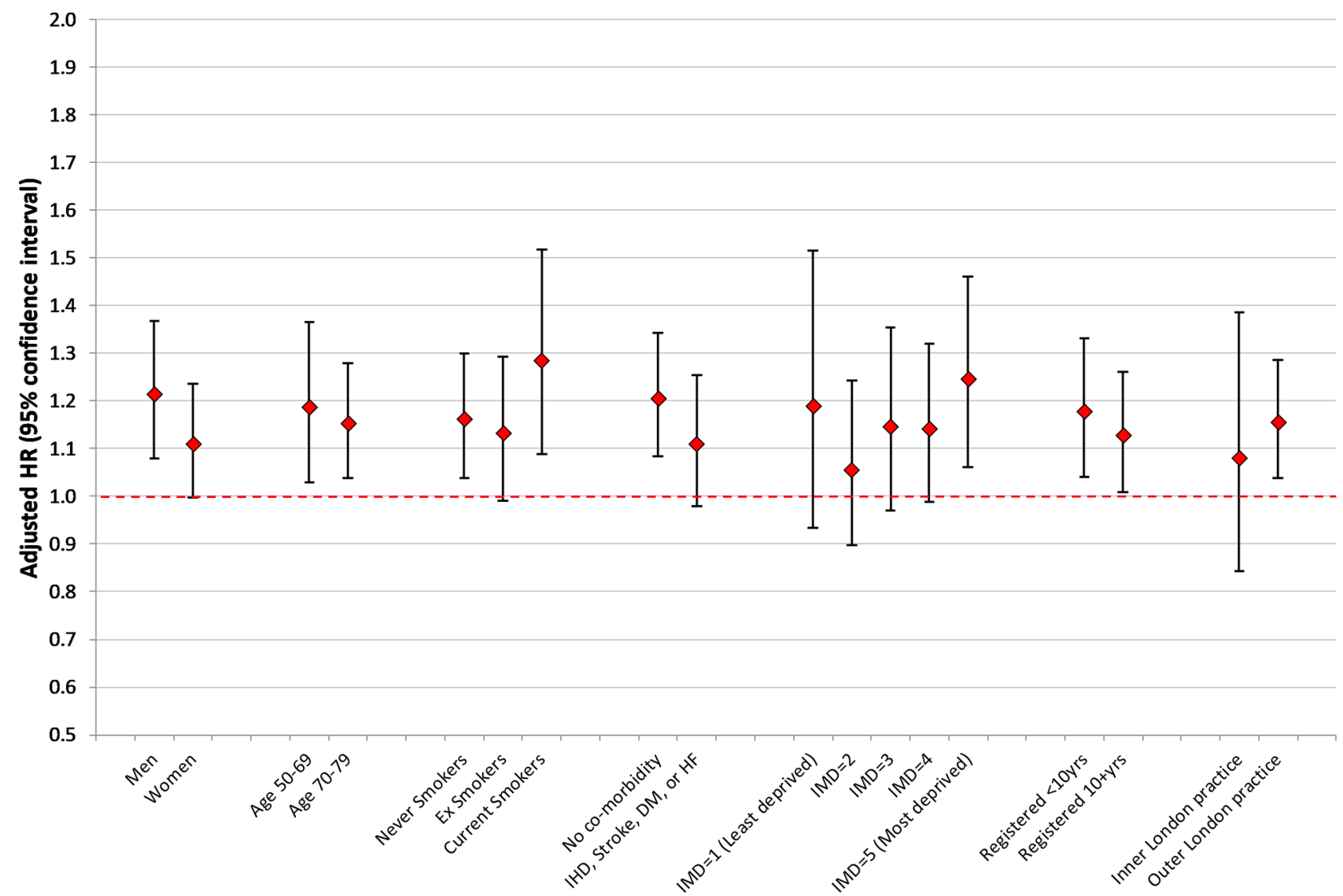

Figure 2 Stratified adjusted HRs for an interquartile increase $\left(7.5 \mu \mathrm{g} / \mathrm{m}^{3}\right)$ in $\mathrm{NO}_{2}$ and all incident dementia during $2005-2013$. HRs estimated from Cox model with practice fitted as shared frailty. Adjusted for age, sex, ethnicity, smoking, body mass index and IMD. P values for interaction tests: age $(p=0.75)$, sex $(p=0.27)$, smoking $(p=0.47)$, comorbidity $(p=0.31)$, IMD $(p=0.72)$, registration length $(p=0.62)$ and practice borough $(p=0.63)$. DM, diabetes mellitus; HF, heart failure; IHD, ischaemic heart disease; IMD, Index of Multiple Deprivation; $\mathrm{NO}_{2}$, nitrogen dioxide.

study we observed a wide range of incident rates by practice $(0.2 \%-8.4 \%)$, and since the majority of air pollution variation was between practices we cannot discount unmeasured practice characteristics as a possible explanation for our findings. There are also known variations in the prevalence and diagnosis rates of dementia across England, ${ }^{24}$ with London being among the reported lowest, ${ }^{29}$ so we also have to acknowledge that the associations we observed may be specific within London and may not extend nationally.

Another weakness of the study is the lack of historical data surrounding exposure. Most large epidemiological studies of long-term exposure to pollution will have difficulty capturing an accurate picture of lifetime or cumulative exposure. This may be pertinent for Alzheimer's disease where the pathogenesis of the disease may take place over many years. ${ }^{30}$ We did not have any information relating to previous address or location, and the London population is thought to be mobile and dynamic over time. ${ }^{31}$ Thus, we are making an assumption that an annual estimate for a single year (2004) represents long-term exposure, based on the last known address for the patient at that practice. We tested this in two ways: (1) sensitivity analyses based on patients who had been continually registered at their practice for a long time ( $>10$ years) produced similar findings; (2) where we did have other modelled years available during follow-up (2005-2010), these were highly correlated over time $(r>0.95)$, so alternative analyses using them made no discernible difference. However, we cannot discount historical factors as an explanation for our findings. For example, it could be that recent exposure levels are acting as a proxy for other historical environmental factors linked to pollution, such as lead from petrol, ${ }^{32}$ where cumulative exposure has been linked to cognitive decline in later life. ${ }^{33}$

A novel aspect of our analysis was the ability to simultaneously study the modelled effects of air and noise pollution on dementia, overcoming acknowledged limitations from other studies. ${ }^{11} 34$ Previous validation of the pollution models used in this study had shown low roadside correlation between them, suggesting that the independent effects of traffic pollution and road noise can be investigated..$^{20}$ However, a potential limitation is that by being based within Greater London, our air pollution exposure estimates may be somewhat homogeneous, lacking the variability we would expect to see nationally when more rural geographical areas are included. Within London, the contribution of regional (background) $\mathrm{PM}_{2.5}$ and $\mathrm{O}_{3}$ to overall levels 
Table 4 HRs for incident Alzheimer's disease, vascular and non-specific dementia during 2005-2013 by air and noise pollutants

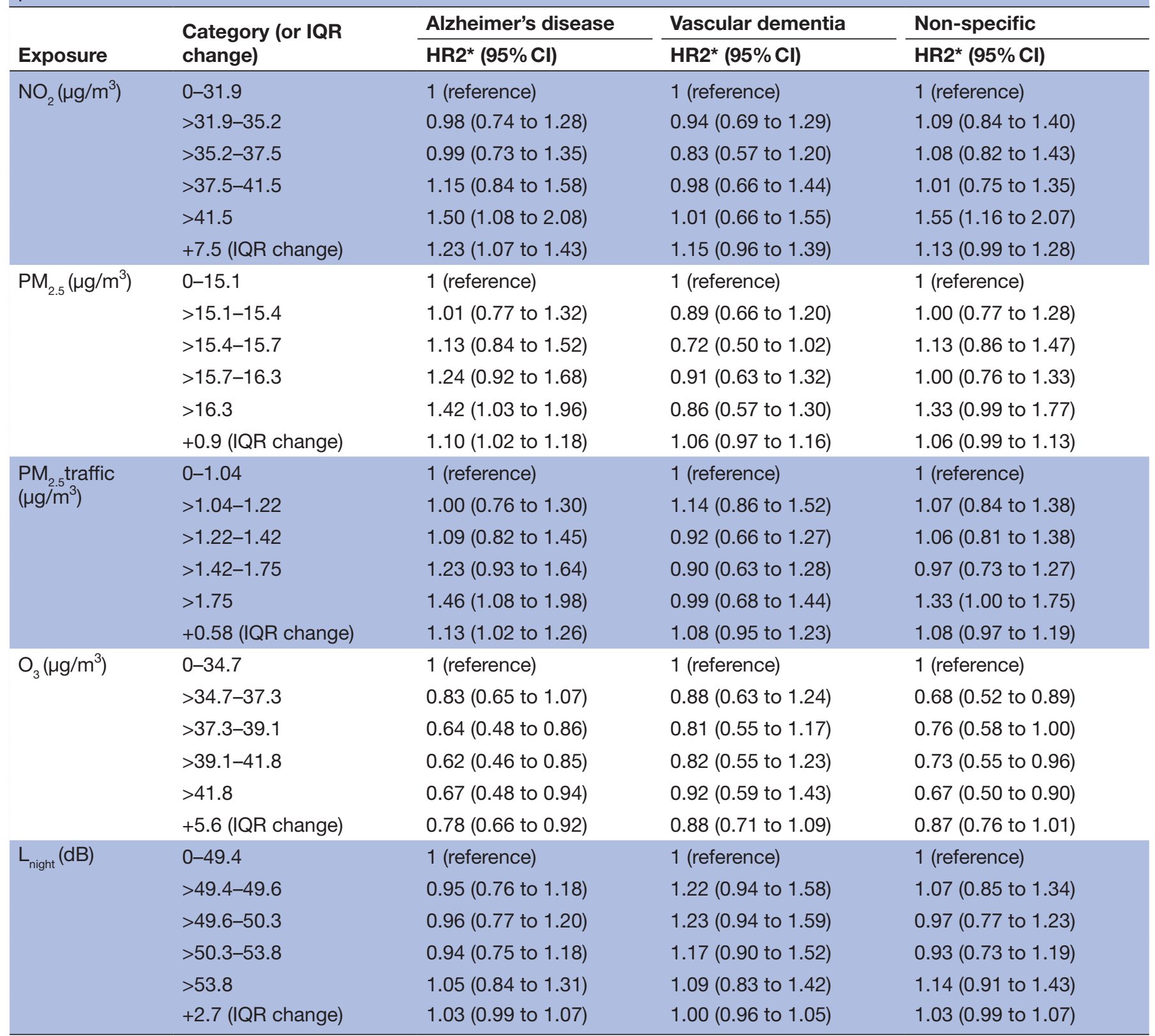

*HR2: Cox model with practice fitted as shared frailty. Adjusted for age, sex, ethnicity, smoking, alcohol consumption, body mass index and Index of Multiple Deprivation. For each exposure, models fit either quintiles with reference category, or IQR change.

$\mathrm{L}_{\text {night }}$, night-time noise levels; $\mathrm{NO}_{2}$, nitrogen dioxide; $\mathrm{O}_{3}$, ozone; $\mathrm{PM}_{2.5}$, particulate matter $\leq 2.5 \mu \mathrm{m}$.

tends to dominate. ${ }^{17}$ However, we were able to make use of a dispersion model with exceptionally fine resolution $(20 \times 20 \mathrm{~m})$ to estimate significant changes in exposure of air pollution such as $\mathrm{NO}_{2}$, between major roads and suburban background locations. ${ }^{17}$ Despite this, the reality was that subtle roadside changes predicted by the model were small in comparison with larger differences estimated between the areas represented by the GP practices (ICCs $>0.7$ for all air pollutants), suggesting most modelled air pollution variation was between (practice) areas. ${ }^{16}$ While this limited statistical power to test for any within-practice effects in the study, we did not find evidence to suggest that the overall associations with $\mathrm{NO}_{2}$ and $\mathrm{PM}_{2.5}$ were entirely explained by between-practice differences in modelled exposures.

Finally, another limitation was the incomplete information on key confounders and reliance on an areabased measure (IMD) for socioeconomic status. While mid-life obesity is a risk factor for Alzheimer's disease, ${ }^{5}$ the BMI measures we extracted around baseline showed that the risk declined with obesity in later life, a finding which has been observed elsewhere. ${ }^{35}$ However, further adjustment for IHD, stroke, diabetes and heart failure, which would be associated with earlier unmeasured risk 
factors, including individual socioeconomic status, did not explain our findings.

\section{Context}

The established body of epidemiological evidence linking long-term concentrations of air pollution to adverse health effects has mainly focused on cardiovascular disease. ${ }^{36}$ The Global Burden of Disease studies, which have described the worldwide impact of air pollution, considered a wide range of outcomes (IHD, stroke, lung cancer, chronic obstructive pulmonary disease) but did not consider neurodegenerative outcomes. ${ }^{7}$ Research linking air pollution exposure to neurocognitive function has gradually increased from observational findings in 2002 from dogs in Mexico City, ${ }^{37}$ to larger studies which assessed cognitive decline, ${ }^{38} 39$ and large population cohorts that specifically investigated the association in relation to diagnoses of dementia. $101140-43$

A 2015 review on the effect of long-term exposure to outdoor air pollution (15 studies) and noise (8 studies) on cognitive and psychological functions in adults showed that both exposures were separately shown to be associated with one or several measures of global cognitive function, but no study considered both exposures simultaneously, which they highlighted as a need for further research. ${ }^{34}$ The same authors followed with data from the Heinz Nixdorf Recall cohort study ${ }^{13}$ on 4086 adults using an additively calculated global cognitive score. They concluded 'air pollution and road traffic noise might act synergistically on cognitive function in adults'. Our study could consider both measures (air pollution and night noise), and while both showed independent associations with dementia, in a combined model any associations with noise were diminished and of borderline statistical significance.

The largest cohort studies to date investigating dementia and long-term exposure to air pollution are from North America. ${ }^{10} 1143$ Chen et $a l^{10}{ }^{11}$ used a large Canadian population-based cohort of over 2 million adults aged $55-85$ years to ascertain approximately 250000 incident dementia cases during 2001-2013. In their first analysis, ${ }^{10}$ the authors found that the risk of dementia increased with nearness to a major road (adjusted $\mathrm{HR}=1.07,95 \% \mathrm{CI}$ 1.06 to 1.08 , for people living $<50 \mathrm{~m}$ from a major traffic road versus $>300 \mathrm{~m}$ ). Associations were stronger among urban residents, especially those who lived in major cities. In a subsequent analysis, ${ }^{11}$ they used land-use regression models to estimate associations between incident dementia and air pollution, finding significant positive associations with both $\mathrm{PM}_{2.5}$ and $\mathrm{NO}_{2}$, and smaller negative associations with $\mathrm{O}_{3}$. An IQR increase in $\mathrm{PM}_{2.5}(4.8 \mu \mathrm{g}$ / $\mathrm{m}^{3}$ ) was associated with an HR of 1.04 (95\% CI 1.03 to 1.05), while for $\mathrm{NO}_{2}$ (14.2 parts per billion) HR was estimated to be 1.10 (95\% CI 1.08 to 1.12). By comparison, our estimated distribution of the same pollutants within Greater London was much less spread, with IQRs approximately one-quarter in size. Therefore, comparative HRs for similar unit changes in our study are much greater (eg, for a $1 \mu \mathrm{g} / \mathrm{m}^{3}$ change in $\mathrm{PM}_{2.5}$ the HR would be 1.07 compared with 1.01 from the Canadian study, for $\mathrm{NO}_{2}$ this would be 1.02 vs 1.00). Our estimate for $\mathrm{PM}_{2.5}$ was more in line what was found in a large US study of Medicare enrollees for first-ever hospitalisation for dementia during 1999-2010 ( $\mathrm{HR}=1.08,95 \%$ CI 1.05 to 1.11 , for a $1 \mu \mathrm{g} / \mathrm{m}^{3}$ change in $\left.\mathrm{PM}_{2.5}\right)$. Chen et al $\mathrm{l}^{11}$ speculate that the stronger associations observed with $\mathrm{NO}_{2}$ may be in part due to it better capturing fine-scale variability in traffic-related air pollution, whereas $\mathrm{PM}_{2.5}$ and $\mathrm{O}_{3}$ have larger regional components. However the resolution of their air pollution models was coarser $(1 \times 1 \mathrm{~km}$ resolution) than in our study $(20 \times 20 \mathrm{~m})$ and may not capture primary emissions from road traffic. While our models were able to estimate traffic-specific components of $\mathrm{PM}_{2.5}{ }^{17}$ effect estimates remained higher for $\mathrm{NO}_{2}$.

Some smaller studies have separated Alzheimer's disease from dementia. In Europe, a 15-year longitudinal study in northern Swedish city found evidence of positive associations with both vascular dementia and Alzheimer's disease and nitrogen oxide using a land-use regression model with a spatial resolution of $50 \times 50 \mathrm{~m} .{ }^{41}$ Comparison between participants in the highest quartile of residential exposure at baseline, versus those in the lowest, produced similar estimates for Alzheimer's disease $(\mathrm{HR}=1.38)$ and vascular dementia $(\mathrm{HR}=1.47)$. There have been recent cohort studies from Taiwan: Jung et $a t^{40}$ showed long-term exposure to $\mathrm{O}_{3}$ and $\mathrm{PM}_{2.5}$ was shown to increase the risk of Alzheimer's disease, while Chang et at found associations between dementia and $\mathrm{NO}_{2}$ and carbon monoxide. A smaller case-control study by $\mathrm{Wu}$ et al ${ }^{44}$ linked $\mathrm{PM}_{10}$ and $\mathrm{O}_{3}$ to an increased risk of Alzheimer's disease and (vascular) dementia. In our study, lower $\mathrm{O}_{3}$ was negatively associated with risk of dementia, primarily as a result of the strong negative correlation with the other modelled air pollutants. ${ }^{45}$

\section{Implications}

The implications of linking exposure to air pollution such as $\mathrm{NO}_{2}$ to the development of dementia, specifically Alzheimer's disease, raise many questions. ${ }^{12}$ The cause of these neurodegenerative diseases is still largely unknown and may be multifactorial. ${ }^{8}$ While toxicants from air pollution have several plausible pathways to reach the brain, how and when they may influence neurodegeneration remains speculative. ${ }^{83}{ }^{46}$ Traffic-related air pollution has been linked to poorer cognitive development in young children, ${ }^{47}$ and continued significant exposure may produce neuroinflammation and altered brain innate immune responses in early adulthood. ${ }^{48}$ In later life, the risk for accelerated cognitive decline may involve gene-environment interactions, such as that with apolipoprotein $\mathrm{E},{ }^{49}$ where evidence comes from findings in neurotoxicological experiments with mice. ${ }^{50}$

Our observation of an association of air pollution with new dementia diagnoses among older adults living in Greater London is in contrast to an earlier analysis on these data which failed to show consistent associations 
between air pollution and cardiorespiratory outcomes. ${ }^{16}$ These suggest there may be a geographical pattern specific to dementia, and potentially Alzheimer's disease, which requires further exploration nationally. In the Ontario cohort, Chen et al estimated that $6.1 \%$ of their total dementia cases were attributable to elevated air pollution exposure. ${ }^{11}$ In our study, a theoretical shift of all patients to the bottom $20 \%$ of $\mathrm{NO}_{2}$ exposure produces an attributable fraction of $7 \%$ (data not shown). While this would be smaller than previous population attributable fraction (PAF) estimates for dementia in the UK for a range of independent risk factors such as for hypertension or obesity, ${ }^{5}$ even a small PAF for dementia would be impactful, where environmental risk factors such as air pollution can be more easily modified at the population level. ${ }^{30}$ There would be significant public health gains even if the impact was only to delay the progression of dementia. ${ }^{4}$

With the future global burden of dementia likely to be substantial, ${ }^{3}$ further epidemiological work is urgently needed to confirm and understand better recent findings linking air pollution to dementia. ${ }^{830}$ Our results suggest both regional and urban background pollutants may be as important as near-traffic pollutants. Future large-scale studies will need to rely on improved recording and linkage of dementia diagnoses across electronic systems, particularly Alzheimer's disease, where multiple sources can improve diagnostic accuracy. ${ }^{25}$ Since exposure is lifelong, and most cases are diagnosed in later life, historical data are also ideally required to better estimate cumulative exposure over preceding decades. In conclusion, our findings add to a growing evidence base linking air pollution and neurodegeneration and should encourage further research in this area.

Contributors HRA, RWA, JG, SDB and FJK contributed to the wider study conception and design. HRA, SDB, JG, DD and FJK contributed to exposure assessment. IMC, RWA and DGC acquired linked health data. IMC conceived the specific study design, conducted the data analyses and drafted the initial report. HRA, RWA, DGC and DPS all contributed to the data analysis plan. All authors contributed to interpreting the analyses and to critically revising the article, and approved the final draft. IMC is the guarantor of the work.

Funding This work was supported by the UK Natural Environment Research Council, Medical Research Council, Economic and Social Research Council, Department for Environment, Food and Rural Affairs, and Department of Health (NE/ I007806/1; NE/I008039/1; NE/I00789X/1) through the Environmental Exposure \& Health Initiative. The research was also part funded by the National Institute for Health Research Health Protection Research Unit (NIHR HPRU) in Health Impact of Environmental Hazards at King's College London in partnership with Public Health England (PHE) and Imperial College London. The views expressed in this paper are those of the authors and not do not reflect the official policy or position of any of the following: the NHS, the NIHR, the Department of Health, Public Health England or the Medicines and Healthcare Products Regulatory Agency (MHRA). Clinical Practice Research Datalink is owned by the Secretary of State of the UK Department of Health and operates within the MHRA. Clinical Practice Research Datalink has received funding from the MHRA, Wellcome Trust, Medical Research Council, NIHR Health Technology Assessment Programme, Innovative Medicines Initiative, UK Department of Health, Technology Strategy Board, Seventh Framework Programme EU, various universities, contract research organisations, and pharmaceutical companies.

Competing interests None declared.

Patient consent Not required.
Ethics approval This study (protocol number 12_026AR) was approved by the Independent Scientific Advisory Committee evaluation of joint protocols of research involving CPRD data in September 2017.

Provenance and peer review Not commissioned; externally peer reviewed.

Data sharing statement Due to data restrictions, we are unable to share any aspect of the data.

Open access This is an open access article distributed in accordance with the Creative Commons Attribution Non Commercial (CC BY-NC 4.0) license, which permits others to distribute, remix, adapt, build upon this work non-commercially, and license their derivative works on different terms, provided the original work is properly cited, appropriate credit is given, any changes made indicated, and the use is non-commercial. See: http://creativecommons.org/licenses/by-nc/4.0/.

\section{REFERENCES}

1. Office for National Statistics. Deaths registered in England and Wales (Series DR): 2015. 2016 https://www.ons.gov.uk/peoplepopulation andcommunity/birthsdeathsandmarriages/deaths/bulletins/deathsre gisteredinenglandandwalesseriesdr/2015\#main-points (Accessed 06-10-17.).

2. Newton JN, Briggs AD, Murray CJ, et al. Changes in health in England, with analysis by English regions and areas of deprivation, 1990-2013: a systematic analysis for the Global Burden of Disease Study 2013. Lancet 2015;386:2257-74.

3. Prince M, Bryce R, Albanese E, et al. The global prevalence of dementia: a systematic review and metaanalysis. Alzheimers Dement 2013;9:63-75.

4. Brookmeyer R, Johnson E, Ziegler-Graham K, et al. Forecasting the global burden of Alzheimer's disease. Alzheimers Dement 2007;3:186-91.

5. Norton S, Matthews FE, Barnes DE, et al. Potential for primary prevention of Alzheimer's disease: an analysis of population-based data. Lancet Neurol 2014;13:788-94.

6. Killin LOJ, Starr JM, Shiue IJ, et al. Environmental risk factors for dementia: a systematic review. BMC Geriatr 2016;16:28.

7. Cohen AJ, Brauer M, Burnett R, et al. Estimates and 25-year trends of the global burden of disease attributable to ambient air pollution: an analysis of data from the global burden of diseases study 2015 . Lancet 2017;389:1907-18.

8. Moulton PV, Yang W. Air pollution, oxidative stress, and Alzheimer's disease. J Environ Public Health 2012;2012:1-9.

9. Power MC, Adar SD, Yanosky JD, et al. Exposure to air pollution as a potential contributor to cognitive function, cognitive decline, brain imaging, and dementia: a systematic review of epidemiologic research. Neurotoxicology 2016;56:235-53.

10. Chen $\mathrm{H}$, Kwong JC, Copes R, et al. Living near major roads and the incidence of dementia, Parkinson's disease, and multiple sclerosis: a population-based cohort study. Lancet 2017;389:718-26.

11. Chen $\mathrm{H}$, Kwong JC, Copes R, et al. Exposure to ambient air pollution and the incidence of dementia: a population-based cohort study. Environ Int 2017;108:271-7.

12. Calderón-Garcidueñas L, Villarreal-Ríos R. Living close to heavy traffic roads, air pollution, and dementia. Lancet 2017;389:675-7.

13. Tzivian L, Jokisch M, Winkler A, et al. Associations of long-term exposure to air pollution and road traffic noise with cognitive function-An analysis of effect measure modification. Environ Int 2017;103:30-8.

14. Herrett E, Gallagher AM, Bhaskaran K, et al. Data resource profile: clinical practice research datalink (CPRD). Int J Epidemiol 2015;44:827-36.

15. Department for Communities and Local Government. English indices of deprivation 2010. London: Department for Communities and Local Government, 2011. (accessed 28 Dec 2015).

16. Carey IM, Anderson HR, Atkinson RW, et al. Traffic pollution and the incidence of cardiorespiratory outcomes in an adult cohort in London. Occup Environ Med 2016;73:849-56.

17. Beevers SD, Kitwiroon N, Williams ML, et al. Air pollution dispersion models for human exposure predictions in London. $J$ Expo Sci Environ Epidemiol 2013;23:647-53.

18. Beevers SD, Dajnak D. Traffic project supplementary files. Air pollution model. KCLurban model description, evaluation and outputs. 2015 https://www.kcl.ac.uk/lsm/research/divisions/aes/ research/ERG/research-projects/traffic/TRAFFIC-SM-Air-pollutionModel.pdf (accessed 14 Feb 2018).

19. Gulliver J, Morley D, Vienneau D, et al. Development of an open-source road traffic noise model for exposure assessment. Environmental Modelling \& Software 2015;74:183-93. 
20. Fecht D, Hansell AL, Morley D, et al. Spatial and temporal associations of road traffic noise and air pollution in London: Implications for epidemiological studies. Environ Int 2016;88:235-42.

21. NHS Digital. Quality and outcomes framework: NHS Digital, 2016. (accessed 06 Dec 2017).

22. Carey IM, Shah SM, Harris T, et al. A new simple primary care morbidity score predicted mortality and better explains between practice variations than the Charlson index. J Clin Epidemiol 2013;66:436-44

23. Austin PC. A tutorial on multilevel survival analysis: methods, models and applications. Int Stat Rev 2017;85:185-203.

24. Walker IF, Lord PA, Farragher TM. Variations in dementia diagnosis in England and association with general practice characteristics. Prim Health Care Res Dev 2017;18:235-41.

25. Sibbett RA, Russ TC, Deary IJ, et al. Dementia ascertainment using existing data in UK longitudinal and cohort studies: a systematic review of methodology. BMC Psychiatry 2017;17:17.

26. Russell P, Banerjee S, Watt J, et al. Improving the identification of people with dementia in primary care: evaluation of the impact of primary care dementia coding guidance on identified prevalence. BMJ Open 2013;3:e004023.

27. Alzheimer's Society. Dementia UK: update. 2nd edn: Alzheimer's Society, 2014. (accessed 10 Apr 2018)

28. Connolly A, Gaehl E, Martin H, et al. Underdiagnosis of dementia in primary care: variations in the observed prevalence and comparisons to the expected prevalence. Aging Ment Health 2011;15:978-84

29. Department of Health. A state of the nation report on dementia care and support in England. 2013 https://www.gov.uk/government/ uploads/system/uploads/attachment_data/file/262139/Dementia.pdf (accessed 10 Apr 2018).

30. Weuve J. Invited commentary: how exposure to air pollution may shape dementia risk, and what epidemiology can say about it. Am J Epidemiol 2014;180:367-71.

31. Bell S, Paskins J. Imagining the future city: London 2062. London: Ubiquity Press, 2013:31.

32. Laidlaw MAS, Poropat AE, Ball A, et al. Exposure to lead in petro and increased incidence of dementia. Lancet 2017;389:2371-2.

33. Bakulski KM, Rozek LS, Dolinoy DC, et al. Alzheimer's disease and environmental exposure to lead: the epidemiologic evidence and potential role of epigenetics. Curr Alzheimer Res 2012;9:563-73.

34. Tzivian $L$, Winkler $A$, Dlugaj $M$, et al. Effect of long-term outdoor air pollution and noise on cognitive and psychological functions in adults. Int J Hyg Environ Health 2015;218:1-11.

35. Dahl AK, Löppönen M, Isoaho R, et al. Overweight and obesity in old age are not associated with greater dementia risk. J Am Geriatr Soc 2008;56:2261-6
36. Newby DE, Mannucci PM, Tell GS, et al. Expert position paper on air pollution and cardiovascular disease. Eur Heart J 2015;36:83-93.

37. Calderón-Garcidueñas L, Azzarelli B, Acuna $\mathrm{H}$, et al. Air pollution and brain damage. Toxicol Pathol 2002;30:373-89.

38. Peters R, Peters J, Booth A, et al. Is air pollution associated with increased risk of cognitive decline? A systematic review. Age Ageing 2015;44:755-60.

39. Ailshire JA, Crimmins EM. Fine particulate matter air pollution and cognitive function among older US adults. Am J Epidemiol 2014;180:359-66.

40. Jung CR, Lin YT, Hwang BF. Ozone, particulate matter, and newly diagnosed Alzheimer's disease: a population-based cohort study in Taiwan. J Alzheimers Dis 2015;44:573-84.

41. Oudin A, Forsberg B, Adolfsson AN, et al. Traffic-Related air pollution and dementia incidence in Northern Sweden: a longitudinal study. Environ Health Perspect 2016;124:306-12.

42. Chang $\mathrm{KH}$, Chang MY, Muo $\mathrm{CH}$, et al. Increased risk of dementia in patients exposed to nitrogen dioxide and carbon monoxide: a population-based retrospective cohort study. PLoS One 2014;9:e103078.

43. Kioumourtzoglou MA, Schwartz JD, Weisskopf MG, et al. Longterm PM2.5 exposure and neurological hospital admissions in the Northeastern United States. Environ Health Perspect 2016;124:23-9.

44. Wu YC, Lin YC, Yu HL, et al. Association between air pollutants and dementia risk in the elderly. Alzheimers Dement 2015;1:220-8.

45. Atkinson RW, Carey IM, Kent AJ, et al. Long-term exposure to outdoor air pollution and incidence of cardiovascular diseases. Epidemiology 2013;24:44-53.

46. Block ML, Elder A, Auten RL, et al. The outdoor air pollution and brain health workshop. Neurotoxicology 2012;33:972-84.

47. Sunyer J, Esnaola M, Alvarez-Pedrerol M, et al. Association between traffic-related air pollution in schools and cognitive development in primary school children: a prospective cohort study. PLoS Med 2015;12:e1001792

48. Calderón-Garcidueñas L, Solt AC, Henríquez-Roldán C, et al. Longterm air pollution exposure is associated with neuroinflammation, an altered innate immune response, disruption of the blood-brain barrier, ultrafine particulate deposition, and accumulation of amyloid beta-42 and alpha-synuclein in children and young adults. Toxicol Pathol 2008;36:289-310.

49. Schikowski T, Vossoughi M, Vierkötter A, et al. Association of air pollution with cognitive functions and its modification by APOE gene variants in elderly women. Environ Res 2015;142:10-16.

50. Cacciottolo $M$, Wang $X$, Driscoll I, et al. Particulate air pollutants, APOE alleles and their contributions to cognitive impairment in older women and to amyloidogenesis in experimental models. Trans/ Psychiatry 2017;7:8 